\title{
Full mouth rehabilitation using monolithic zirconia: a clinical report
}

\author{
Won-Seok Oh, Jae-Jun Ryu* \\ Division of Prosthodontics, Department of Dentistry, Anam Hospital, Korea University Medical Center, Seoul, Republic of Korea
}

Previously, the usage of monolithic zirconia in anterior restoration was limited because of problems such as the monotony of tones and shades which would compromise the outcome of esthetic purpose. Zirconia was merely used as a coping with additional porcelain veneering whereas porcelain chipping cannot be evaded. Recently, with the improvement of monolithic zirconia, the various translucency and tones made it possible to use zirconia for anterior restoration. In this case, a male patient of 63 years old received a full mouth rehabilitation with monolithic zirconia. After a period of time usage, the outcome showed a favorable result functionally and esthetically. (J Dent Rehabil Appl Sci 2015;31(4):358-63)

Key words: full mouth rehabilitation; monolithic zirconia, computer-aided design/computer-aided manufacturing

\section{서론}

기존 임플란트 및 자연치 수복시의 재료로는 금전장관 과 도재소부가공의치(porcelain fused to metal crown)가 주로 사용되었다. 하지만 금전장관의 경우 낮은 심미성 과 재료비의 상승으로 사용이 점차 줄어들고 있으며 또 한 도재소부가공의치의 경우 도재 파절의 문제점이 항상 존재한다. ${ }^{1,2}$ 더구나 현재는 보철물에 대한 기능 및 심미 성 모두에 대한 요구가 점차 증가되는 있는 실정이며 이 에 맞춰 도재 재료 또한 점차 발전해나가고 있다. ${ }^{3}$ 이러 한 발전에 의해 최근에 소개되는 Computer-Aided Design/ Computer-Aided Manufacturing (CAD/CAM)에 의해 제작되는 단일 구조 지르코니아는 임상에 사용해도 충분 할 만한 강도가 보고되고 있다. ${ }^{4,5}$ 또한 점차 투과도 및 색 조가 개선되어 기존 지대치의 투명도가 낮은 특정군에서 는 도재 피개 없이도 전치부 사용이 가능해졌다. ${ }^{6}$

본 증례는 단일 구조 지르코니아를 이용하여 전악 보 철 수복을 시행해 기능적으로나 심미적으로 만족스러운

*Correspondence to: Jae-Jun Ryu

Professor, Department of Prosthodontics, Anam Hospital Korea University, 145 Anam-ro, Seongbuk-gu, Seoul, 02841, Republic of Korea Tel: +82-2-920-5423, Fax: +82-2-921-7348, E-mail: koprosth@unitel.co.kr Received: June 16, 2015/Last Revision: September 10, 2015/Accepted: December 5,2015
결과를 얻었기에 이를 보고하고자 한다.

\section{증례 보고}

상악 좌측 부위 저작시 통증을 주소로 내원한 63세 남 성 환자로 전신질환은 없었으며 비기능적 습관으로는 야 간 이갈이 습관이 있었다. 임상 및 방사선학적 검사상 치 주질환으로 인한 다수 치아 동요도 및 치아 마모 소견을 보이고 있었으며 특히 상하악 양측 중절치, 측절치, 하악 좌측 제1대구치에 심한 치조골 흡수 소견을 보였다(Fig. 1,2).

정확한 진단 및 치료계획을 세우기 위해 반조절성 교합기(Protar evo5, KaVo Dental GmbH, Biberach, Germany)에 안궁이전 후 진단모형을 마운팅 후 진단왁 스업을 시행하였다(Fig. 3). 이에 치료계획으로는 전체적 인 치주치료 및 야간 이갈이 습관으로 인한 근긴장을 없 애고 치료위를 확립할 수 있도록 하는 교합안정장치 착 용, 정상적인 교합평면에서 벗어난 위치에 있는 하악 좌

Copyright@ 2015 The Korean Academy of Stomatognathic Function and Occlusion. (c) It is identical to Creative Commons Non-Commercial License. 

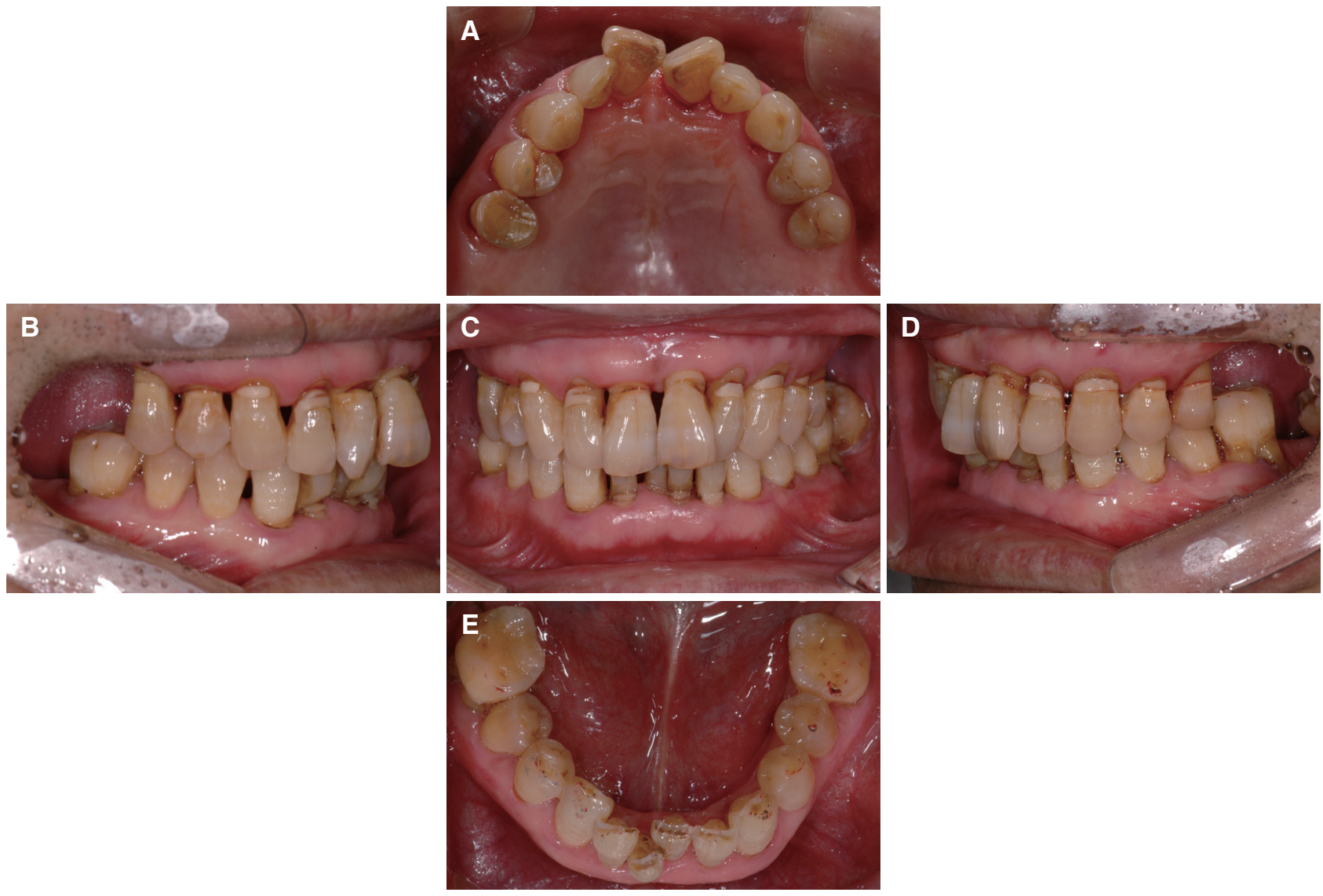

Fig. 1. Pretreatment intraoral view. (A) Maxillary occlusal view, (B) Right lateral view, (C) Frontal view, (D) Left lateral view, (E) Mandibular occlusal view.

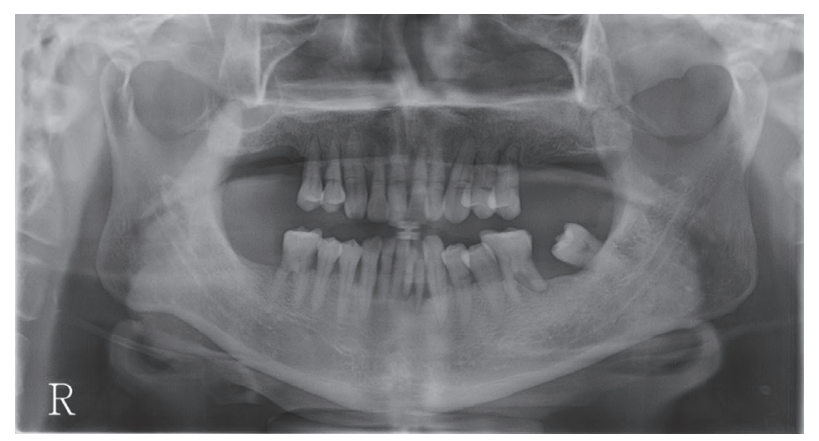

Fig. 2. Pretreatment panoramic radiographic image.
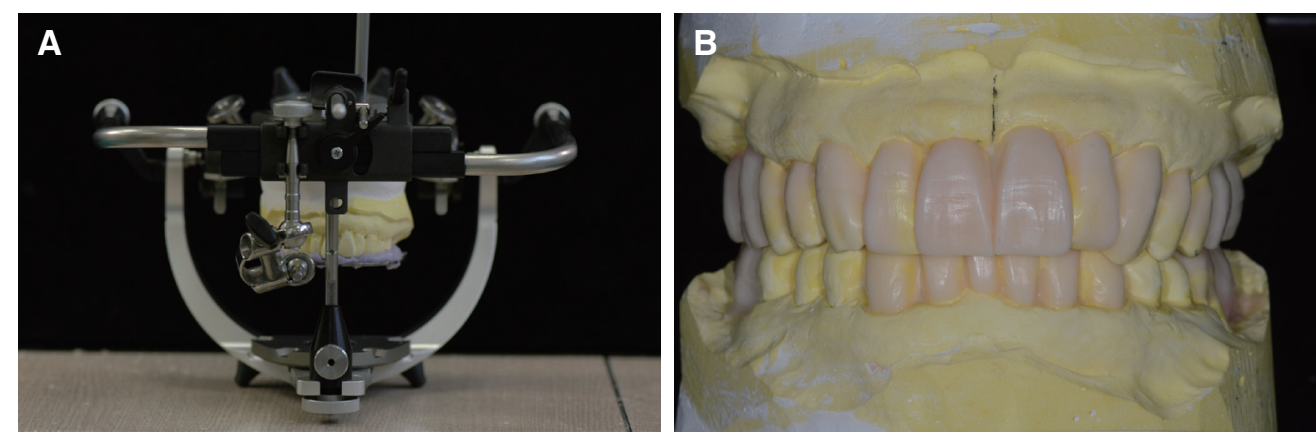

Fig. 3. Diagnostic cast articulation. (A) Facebow transfer, (B) Diagnostic wax up. 
측 제 3 대구치 발치 및 심한 골흡수 양상을 보이는 상하 악 양측 중절치, 측절치, 하악 좌측 제 1 대구치의 발치 를 계획하였다. 그 후 중심 교합위 확립에 의한 저작 기 능 회복, 전치 유도를 확립하는 상악 좌우측 제 1,2 대구 치부위 및 하악 좌측 제 1,2 대구치부위 임플란트 식립을 동반한 전악보철수복계획을 세웠다.

치료계획에 따라 우선 턱관절 안정 및 치료위 결정 을 위한 교합안정장치를 제작해 약 12 주간 장착을 시 행하였다. 이 기간동안 치주치료 및 하악 좌측 제 1,3 대 구치 발치, 진단왁스업상에 계획된 위치에 임플란트 식 립을 위한 방사선 촬영용 스텐트를 제작하고 컴퓨터 단 층 방사선 사진 촬영 통해 골량과 골질 분석을 시행한 후, 방사선 촬영용 스텐트를 변형하여 임플란트 수술 용 가이드를 제작하였다. 이 임플란트 수술용 가이드 를 이용해 계획된 위치에 임플란트(Neo CMI Implant NeoBiotech, Seoul, Korea)를 식립할 수 있었다.

임플란트 식립 후 상, 하악 양측 중절치, 측절치 발 치 및 잔존치 삭제 후 임시치관(Alike, GC Co., Tokyo, Japan)을 제작하였다. 약 12 주간의 교합안정장치 사용 으로 턱관절 안정을 통한 치료위 확립 후에는 최종 보철 형태 확립을 위한 임시치관 재제작을 시행하였다. 이러 한 임시치관 재제작을 위하여 상, 하악 폴리비닐실록산 치과용 고무 인상재(Delikit, Heppiden, Seoul, Korea)로 인상채득을 시행하였다. 작업 모형은 제4형 경석고 $(\mathrm{GC}$ Fujirock EP, GC Europe N.V., Leuven, Belgium)로 제 작하였다. 그 후 견치 유도가 부여된 임시치관 재제작을 위한 왁스업을 시행하고 이를 자가중합레진(Alike, GC $\mathrm{Co}$.)으로 제작하여 구강내에서 조정 후 장착하였다(Fig. $4,5)$.
임시치관 장착 약 8주 후 환자가 편안함을 느끼고 기 능적으로나 심미적으로 문제점이 발견되지 않아 안정 되었다고 판단하였고 적응된 보철물의 형태를 재현하 기 위해 임시치관을 구강 내 장착한 상태로 악간 관계 를 채득하였다. 임시치관 인상채득 후 작업 모형과 반조 절성교합기(Protar evo5, KaVo Dental $\mathrm{GmbH}$ )에 크로 스마운팅을 시행하였다. 최종 고정성 보철물의 재료 선 택의 기준은 환자의 요구 및 상태를 고려한 술자의 종합 적인 판단으로 이루어진다. 본 증례의 경우 야간 이갈이 습관으로 도재 파절이 우려되었고 환자의 기존 지대치 의 투명도가 높지 않았으며 환자의 주된 요구도 심미적 으로 뛰어난 보철물 보다는 단단한, 깨지지 않는 보철물 이었다. 그렇기 때문에 최종 보철물의 재료로는 단일 구 조 지르코니아를 선택하였다. 따라서 최종 보철물은 단 일 구조 지르코니아 블록(BruxZir, Glidewell, Newport Beach, USA)을 사용해 CAD/CAM 방식으로 제작하였 다(Fig. 6).

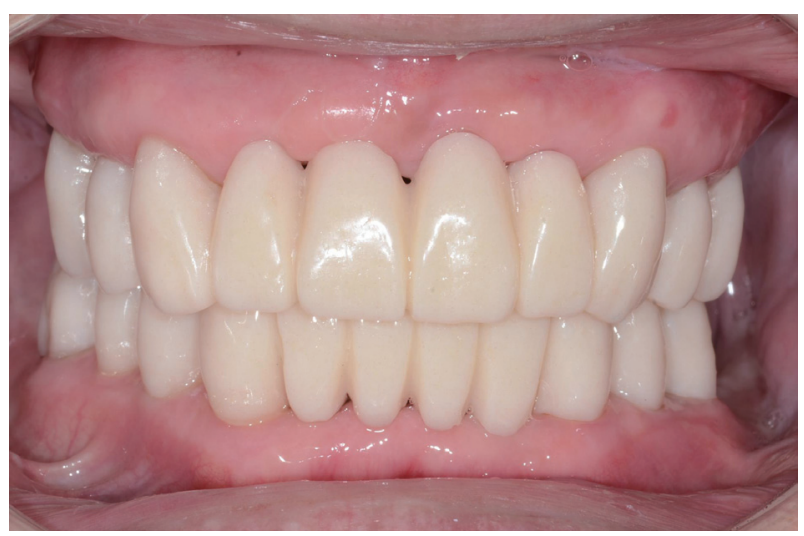

Fig. 5. Provisional restoration delivery.

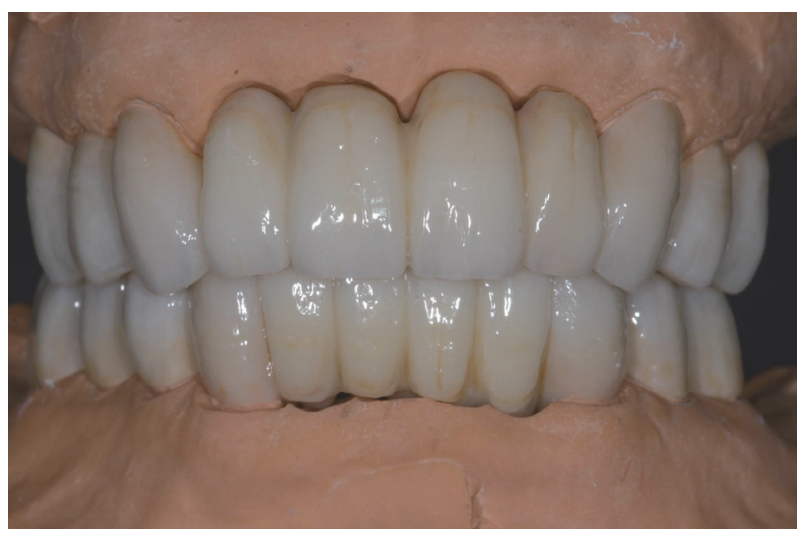

Fig. 6. Monolithic zirconia crown on master cast.

Fig. 4. Full contour wax up on master cast. 

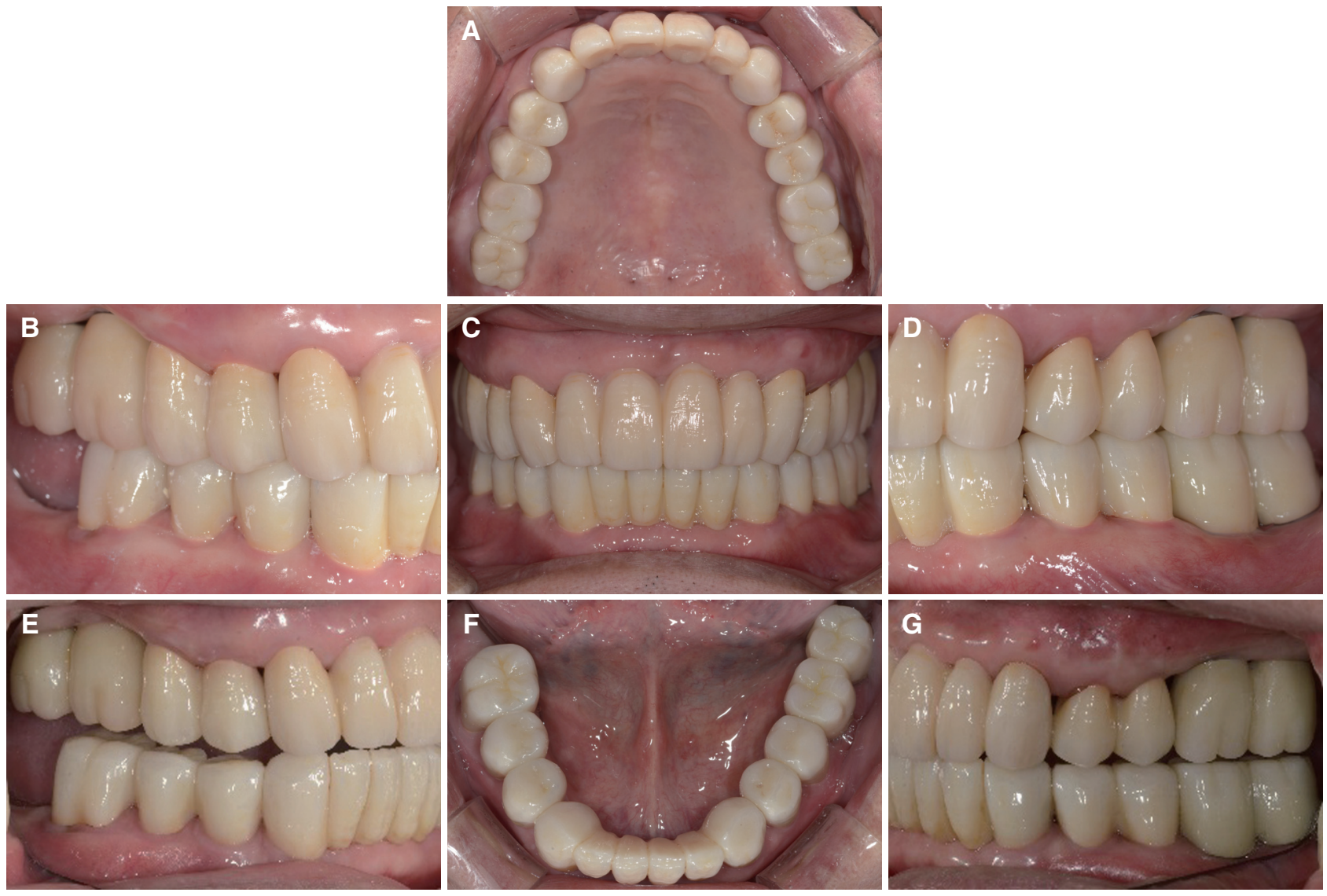

Fig. 7. Esthetics and function were restored with monolithic zirconia crown. (A) Maxillary occlusal view, (B) Right lateral view, (C) Frontal view, (D) Left lateral view, (E) Right lateral movement view, (F) Mandibular occlusal view, (G) Left lateral movement view.

자연치 수복후 구치부 임플란트부위는 임플란트 주 변 연조직 형태를 지대주에 재현가능한 개인 맞춤형 지 대주 제작을 위한 최종인상을 폴리비닐실록산 치과용 고무 인상재(Delikit, Happiden, Seoul, Korea)로 상, 하 악을 다시 인상채득하였다. 인상체 내의 연조직은 폴 리비닐실록산(Gi-mask, Coltene, Mahwah, USA)으로 재현되었고, 작업 모형은 제4형 경석고(GC Fujirock EP, GC Europe N.V.)로 제작하였다. 지대주는 티타 늄 CAD/CAM 밀링 지대주(Myplant, Raphabio Co., Seoul, Korea)로 제작하였고 상부보철물은 마찬가지로 단일 구조 지르코니아(BruxZir, Glidewell)를 이용해 최 종제작하였다. 최종보철물을 환자의 구강내에 장착시에 는 정확한 교합부여를 위하여 T-Scan III (Teksacn, Inc., South Boston, USA)를 이용해 좌우 구치부에서 균등하 게 교합되고 측방운동시 견치유도가 되도록 교합조정을 시행하였다(Fig. 7,8$)$. 최종 접착시에는 단일 구조 지르 코니아 내면에 샌드블러스트 처리 및 지르코니아 프라

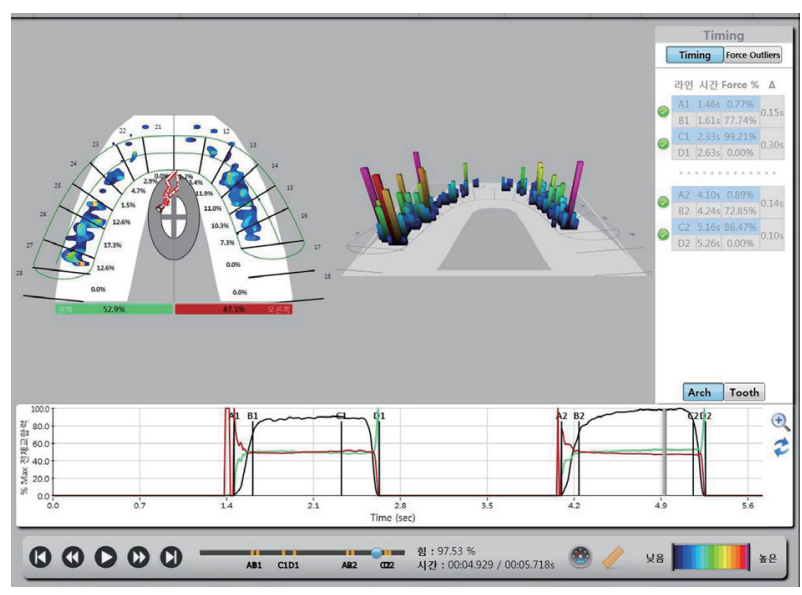

Fig. 8. Occlusal adjustment using T-scan III.

이머(Zirconia liner, Sun medical Co., Shiga, Japan) 처리 후 레진 시멘트(RelyX unicem, 3M, St. Paul, USA)를 사 용하여 접착하였다. 장착 후 구강위생 관리에 관한 교육 


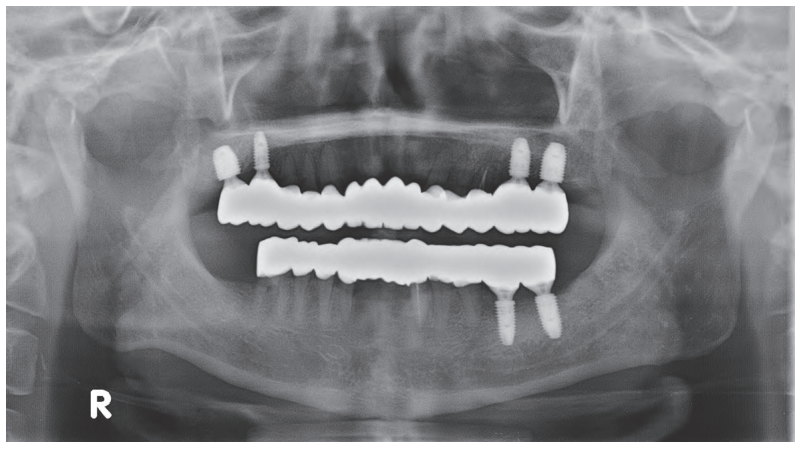

Fig. 9. Postoperative panoramic radiographic image.

을 시행하였고 현재 18 개월의 임상적 및 방사선상의 주 기적 경과 관찰이 이루어지고 있으며, 환자와 술자 모두 심미적, 기능적으로 만족할만한 결과를 얻을 수 있었다 (Fig. 9).

\section{고찰}

단일 구조 지르코니아는 낮은 빛 투과도와 심미성으 로 인해 구치부에 제한적으로 사용되거나 도재 피개가 필요한 코핑의 형태로만 사용되어 왔다. 하지만 도재 피 개를 하는 경우 도재소부가공의치 보철물과 마찬가지로 도재 파절의 문제점이 존재하며 일부 연구에서는 오히 려 도재소부가공의치 보철물보다 더 높은 도재 파절 발 생률을 보고하기도 하였다.

이러한 문제점 때문에 도재 파절을 막기 위한 코핑 디 자인에 대한 연구 및 지르코니아와 도재간의 열팽창계 수 차이를 줄이는 방법에 대한 연구 등이 이루어지고 있 으나 아직은 이러한 연구결과 모두 추가적인 연구가 필 요한 실정으로 도재 파절을 막기 위해 소개된 확실한 방 법은 없다. ${ }^{8}$ 이로 인해 도재 파절을 피하기 위한 다른 방 법으로 도재 피개가 필요 없는 빛 투과도가 향상된 단 일 구조 지르코니아 블록이 개발되고 있으며 현재까지 는 도재 파절을 막기 위한 가장 확실한 방법이다. 하지 만 아직까지는 빛 투과도가 리튬 다이실리케이트에 비 해 낮아 심미성이 높은 보철물을 원하는 환자에 사용하 기에는 어려움이 있다. ${ }^{6}$ 이에 따라 심미성을 원하는 환 자에게 단일 구조 지르코니아 수복을 위해서는 기계적 강도의 손실 없으며 또한 빛 투과도가 리튬 다이실리케 이트 보다 낮지 않은 추가적인 단일 구조 지르코니아 블 록의 개발이 필요할 것으로 보인다.

\section{결론}

본 증례의 경우 비록 단기간의 추적 검사를 시행한 한 계는 있으나 환자의 심미적 요구가 기계적 강도에 대한 요구에 비해 낮으며 이상 기능 습관으로 도재 파절의 위 험성이 높은 경우 단일 구조 지르코니아로 전악 수복을 시행하여 기능적으로나 심미적으로 만족할 만한 결과를 얻을 수 있음을 보여준다.

\section{ORCID}

Won-Seok Oh http://orcid.org/0000-0002-9597-374X

\section{References}

1. Linkevicius T, Vladimirovas E, Grybauskas S, Puisys A, Rutkunas V. Veneer fracture in implantsupported metal-ceramic restorations. Part I: Overall success rate and impact of occlusal guidance. Stomatologija 2008;10:133-9.

2. Llobell A, Nicholls JI, Kois JC, Daly CH. Fatigue life of porcelain repair systems. Int J Prosthodont 1992;5:205-13.

3. Spear F, Holloway J. Which all ceramic system is optimal for anterior esthetics? J Am Dent Assoc 2008;139:19-24.

4. Miyazaki T, Nakamura T, Matsumura H, Ban S, Kobayashi T. Current status of zirconia restoration. J Prosthodont Res 2013;57:236-61.

5. Baldissara P, Llukacej A, Ciocca L, Valandro FL, Scotti R. Translucency of zirconia copings made with different CAD/CAM systems. J Prosthet Dent 2010;104:6-12.

6. Sravanthi Y, Ramani YV, Rathod AM, Ram SM, Turakhia $\mathrm{H}$. The comparative evaluation of the translucency of crowns fabricated with three different all-ceramic materials: an in vitro study. J Clin Diagn Res 2015;9:zc30-4.

7. Larsson C, Vult von Steyern P, Sunzel B, Nilner K. All-ceramic two- to five-unit implant-supported reconstructions. A randomized, prospective clinical trial. Swed Dent J 2006;30:45-53.

8. Zarone F, Russo S, Sorrentino R. From porcelainfused-to-metal to zirconia: clinical and experimental considerations. Dent Mater 2011;27:83-96. 


\section{Monolithic zirconia를 이용한 전악 보철 수복: a clinical report}

\section{오원석, 류재준*}

고려대학교 안암병원 치과보철과

이전 단일 구조 지르코니아는 색조의 단조로움 등 심미성의 문제로 전치부 사용에서 어려움이 있었다. 이에 전치부 증 례의 지르코니아는 코핑으로만 주로 이용되어 최종보철물은 추가적인 도재 피개가 필요했었다. 이에 따라 도재 파절 등의 문제가 존재하였으나 점차 단일 구조 지르코니아 자체의 투과도와 색조가 개선되어 도재 피개 없이도 사용이 가 능해졌다. 본 증례는 63세 남성환자로 단일 구조 지르코니아를 이용하여 전악 보철 수복을 시행해 기능적으로나 심미 적으로 만족스러운 결과를 얻었기에 이를 보고하는 바이다.

(구강회|복응용과학지 2015;31 (4):358-63)

주요어: 전악 수복; monolithic zirconia; computer-aided design/computer-aided manufacturing 